\title{
Feasibility and Acceptability of a Remotely Delivered, Web-Based Behavioral Intervention for Men With Prostate Cancer: Four-Arm Randomized Controlled Pilot Trial
}

June M Chan $^{1 *}$, ScD; Erin L Van Blarigan ${ }^{1 *}$, ScD; Crystal S Langlais ${ }^{1}$, MPH; Shoujun Zhao ${ }^{1}$, PhD; Justin W Ramsdill ${ }^{2}$, MS; Kimi Daniel ${ }^{2}$, MS, ATC; Greta Macaire ${ }^{1}$, MA, RD, CSO; Elizabeth Wang ${ }^{3}$, MPH; Kellie Paich ${ }^{4}$, MPH; Elizabeth R Kessler ${ }^{5}$, MD; Tomasz M Beer ${ }^{2}$, MD; Karen S Lyons ${ }^{6}$, PhD; Jeanette M Broering ${ }^{1}$, RN, PhD, MPH; Peter R Carroll ${ }^{1}$, MD, MPH; Stacey A Kenfield ${ }^{1 *}, \mathrm{ScD}$; Kerri M Winters-Stone ${ }^{2 *}, \mathrm{PhD}$

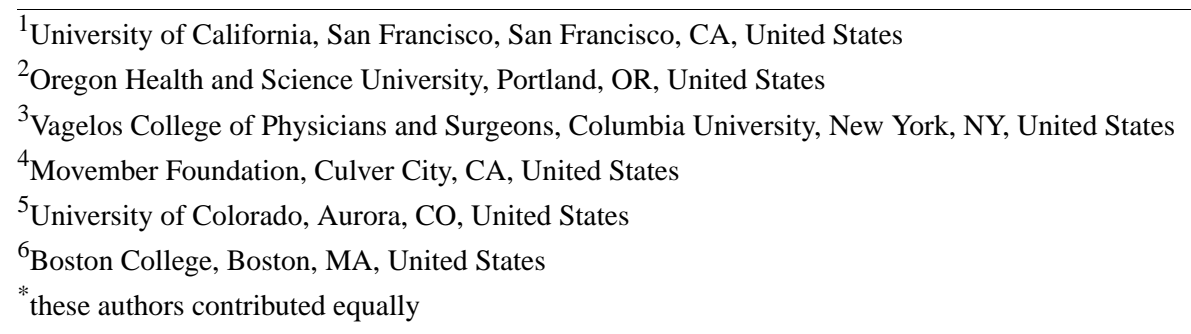

Corresponding Author:

Erin L Van Blarigan, ScD

University of California, San Francisco

UCSF Box 0560

550 16th St. 2nd Floor

San Francisco, CA, 94158

United States

Phone: 14154761111 ext 13608

Email: erin.vanblarigan@ucsf.edu

\section{Abstract}

Background: Diet and exercise may be associated with quality of life and survival in men with prostate cancer.

Objective: This study aimed to determine the feasibility and acceptability of a remotely delivered web-based behavioral intervention among men with prostate cancer.

Methods: We conducted a multi-site 4-arm pilot randomized controlled trial of a 3-month intervention (TrueNTH Community of Wellness). Eligibility included self-reported prostate cancer diagnosis, having a personal device that connected to the internet, age $\geq 18$ years, and ability to read English and receive text messages and emails. Men receiving chemotherapy or radiation, or those who reported contraindications to exercise, could participate with physician clearance. Participants were randomized $(1: 1: 1: 1)$ to additive intervention levels: website; website and personalized diet and exercise prescription; website, personalized prescription, Fitbit, and text messages; and website, personalized prescription, Fitbit, text messages, and 2 30-minute phone calls - one with an exercise trainer and one with a registered dietician. Primary outcomes were feasibility (accrual and attrition) and acceptability (survey data and website use). We described self-reported diet and exercise behavior at the time of enrollment, 3 months, and 6 months as secondary outcomes.

Results: In total, 202 men consented and were randomized between August 2017 and September 2018 (level 1: 49, level 2: 51, level 3: 50, level 4: 52). A total of 160 men completed the onboarding process and were exposed to their randomly assigned intervention $(38,38,42$, and 42 in levels $1,2,3$, and 4, respectively). The follow-up rate was 82.7\% (167/202) at 3 months and $77.2 \%(156 / 202)$ at 6 months. Participants had a median age of 70 years and were primarily White and college educated. Website visit frequency over the 3-month intervention period increased across levels (median: 2, 9, 11, and 16 visits for levels 1, 2, 3, and 4, respectively). Most were satisfied or very satisfied with the intervention $(20 / 39,51 \% ; 27 / 42,64 \%$; 23/44, 52\%; and 27/42, $64 \%$ for levels $1,2,3$, and 4 , respectively). The percentage of men who reported being very satisfied was highest among level 4 participants $(10 / 42,24 \%$ vs $4 / 39,10 \% ; 5 / 42,12 \%$; and $5 / 44,11 \%$ for levels 1,2 , and 3 , respectively). Dissatisfaction was highest 
in level $1(5 / 39,13 \%$ vs $1 / 42,2 \% ; 3 / 44,7 \%$; and $2 / 42,5 \%$ for levels 2,3 , and 4 , respectively). We observed small improvements in diet and physical activity at 3 months among men in level 4 versus those in level 1.

Conclusions: A web-based, remotely delivered, tailored behavioral intervention for men with prostate cancer is feasible. Future studies are warranted to increase the effect of the intervention on patient behavior while maintaining sustainability and scalability as well as to design and implement interventions for more diverse populations.

Trial Registration: ClinicalTrials.gov NCT03406013; http://clinicaltrials.gov/ct2/show/NCT03406013

(J Med Internet Res 2020;22(12):e19238) doi: 10.2196/19238

\section{KEYWORDS}

diet; physical activity; exercise; lifestyle; cancer; survivorship; text messages; internet

\section{Introduction}

\section{Background}

Prostate cancer affects more than 3.6 million men in the United States, making it the most prevalent cancer in American men [1]. Prostate cancer is characterized by low age-adjusted death rates and a relatively long median survival time of 16 years, although this varies greatly by stage at diagnosis [2]. Over this period, men with prostate cancer may experience significant disease- or treatment-related decline in quality of life [3-6], including incontinence, erectile dysfunction, fatigue, poor metabolic functioning, reduced bone and muscle integrity, hot flushes, sexual dysfunction, and low mood [7].

\section{Prior Work}

A growing number of studies have suggested the benefits of a healthy diet and regular exercise for men with prostate cancer, including lower risk of treatment-associated side effects [8-11], cancer progression [12], and cancer-specific mortality [13-16]. Specific dietary factors that have been associated with improved clinical outcomes in men with prostate cancer include higher intake of cruciferous vegetables, vegetable fat, fish, and cooked tomatoes and lower intake of processed meat, whole milk, and poultry with skin [17-25]. Physical activity recommendations of $\geq 150$ minutes of moderate intensity or $\geq 75$ minutes of high-intensity aerobic exercise per week have also been associated with a lower risk of mortality in men with prostate cancer [26].

Translation of this growing evidence of possible benefits of a healthy lifestyle for prostate cancer survivors into clinical practice and survivorship programs has been slow. Although physical activity and nutrition guidelines exist for cancer survivors [27], lifestyle counseling and exercise programs are not standard care practices for individuals with cancer in the United States. Moreover, most prostate cancer survivors do not follow the recommendations.

Previous studies on lifestyle interventions suggest that center-based interventions are effective but require infrastructure that may only be available in urban academic centers [28]. In contrast, it is challenging to make home-based interventions comprehensive or tailored to the individual needs and interests of the participants [29]. The diverse attitudes and motivations to change behavior among men with prostate cancer further complicate matters. Previous studies suggest that although men with prostate cancer appreciate the importance of exercise, most do not feel that the information provided by their doctor is specific enough to be actionable [30]; many also report low motivation for physical activity [30].

\section{Objectives}

In this context, web-based interventions are emerging as promising, scalable modalities for behavior change [31-36]. Prior literature suggests that tailoring of an intervention to individual characteristics and goals and combining technology with personal guidance (ie, blended intervention) may lead to improved outcomes [37-39]. However, questions regarding the feasibility and acceptability of remotely delivered web-based interventions remain, particularly in older adult populations. Thus, we designed the TrueNTH Community of Wellness study, a 4-arm, multi-site, pilot randomized controlled trial to evaluate the feasibility and acceptability of a 3-month web-based intervention for men with prostate cancer with progressive levels of behavioral support. In this study, we report our primary results on the feasibility and acceptability of the intervention. Second, we describe self-reported levels of physical activity and diet at the time of enrollment and 3 and 6 months after the enrollment and explore changes in lifestyle behaviors over the study period.

\section{Methods}

\section{Study Design, Population, and Recruitment}

We conducted a 4-arm pilot randomized controlled trial of a 3-month intervention among men with prostate cancer (ClinicalTrials.gov NCT03406013) to compare 3 levels of increasing behavioral support (levels 2-4) with general educational information on a website (level 1). The multicenter trial was conducted at Oregon Health Sciences University (OHSU), University of California San Francisco (UCSF), and University of Colorado Denver (UCD).

The trial protocol has been reported [40]. Briefly, men were recruited through hospital cancer registry databases, the Cancer of the Prostate Strategic Urologic Research Endeavor registry of men with prostate cancer, and in clinics. Men were eligible to participate if they self-reported a prostate cancer diagnosis, had a personal device with internet and text messaging capabilities and a personal email address, were aged $\geq 18$ years, and were able to read English. Men currently receiving chemotherapy or radiation therapy or those who had potential contraindications to exercise identified on the basis of the 
American College of Sports Medicine exercise preparticipation screening criteria could participate with physician clearance.

OHSU was the primary coordinating center for this trial. All participants provided written consent, and all study-related activities were performed in accordance with and under the supervision of the institutional review board of each study site.

\section{Randomization and Blinding}

Consenting men were block randomized (1:1:1:1) by site (UCSF, OHSU, or UCD) to increasing levels of web-based behavioral support (level 1-4). The randomization scheme was computer generated with block size 4 by SZ and stored at UCSF. When a participant had completed consent and enrollment procedures, research staff at OHSU requested the next assignment from UCSF. Participants were told that they would be randomly assigned to different tools and resources but were unaware of which resources they received relative to other participants.

\section{Intervention Description}

Details on the intervention, including its theoretical basis, have been previously reported [40]. Briefly, level 1 (reference group) received general educational information about exercise and diet, a resource directory, and study-specific guidelines delivered through the website (information on the website was not changed throughout the study period for level 1). Level 2 received the information provided to level 1 along with a personalized diet and exercise prescriptions delivered through the website, including videos of recommended exercises and a weekly short survey about their progress toward the diet and exercise recommendations. Level 3 received information and resources provided to level 2 along with a Fitbit Alta (Fitbit Inc) with physical activity reports (Fitbit data integrated into the website), supportive text messages (50 texts over 90 days: average 4 per week, no response required, equally split and alternating between diet and exercise topics), and weekly web-based short surveys for participants to track their progress toward the diet and exercise recommendations. Level 4 received information and resources provided to level 3 as well as 2 optional 30-minute calls: one with an exercise trainer (KD) and one with a registered dietician (GM). Men accessed the study website with a username and password and had to complete an onboarding process to gain access to the intervention website. The study website home page included a dashboard that summarized self-reported diet and physical activity behavior using visuals and contained links to other pages (eg, Report Progress, See Progress, Connect Fitbit, etc), depending on the assigned level. All participants from all levels received an instruction sheet (PDF) orienting them to the website at enrollment and a weekly email reminder to encourage them to use the website.

The intervention recommendations focused on diet and physical activity. The dietary recommendations provided to all levels were to consume one serving each of healthy vegetable fats and cruciferous vegetables per day; 2 servings each of cooked tomatoes and fish per week; and no whole milk, processed meat, or poultry with skin. The individual dietary prescriptions provided to levels 2 to 4 were focused on helping the participants achieve these recommendations, considering what the participants self-reported at baseline. The physical activity recommendations, consistent with national guidelines, were to engage in 150 minutes of aerobic exercise per week, 60 minutes of strength training per week accumulated in $\geq 2$ sessions, and 2 sessions of stretching per week. The individual exercise prescriptions provided to levels 2 to 4 were based on the men's self-reported current physical activity levels, health goals for exercise, health status, resources for exercise, and time available for exercise. In addition, the exercise prescriptions were tailored to participants' self-reported current prostate cancer status. Men with bone metastases or active cancer treatment other than androgen deprivation therapy were prescribed low-intensity programs.

\section{Web-Based Survey Assessments}

Participants were asked to complete surveys on the internet at baseline, 3 months (immediately following the intervention), and 6 months using the study website and Research Electronic Data Capture [41]. Surveys included sociodemographics and prostate cancer diagnosis and treatment (baseline only), the Community Health Activities Model Program for Seniors (CHAMPS) [42], and a validated food frequency questionnaire (FFQ) [43]. Each month, the men also completed a web-based survey about adverse events (AEs) and whether any reported $\mathrm{AE}$ was related to a pre-existing condition present before enrollment. After 3 months, men were asked to complete a web-based acceptability survey specific to the level of intervention received.

\section{Primary Outcomes: Feasibility and Acceptability}

The primary study outcomes were feasibility and acceptability of the intervention. Feasibility was assessed based on the accrual time and retention. Accrual was defined as the time between enrollment of the first and last participant; our goal was to accrue 200 participants in 12 months. Retention was defined as the proportion of participants who completed at least one of the surveys at each follow-up time point ( 3 and 6 months). A priori, we specified that we would consider the intervention to be feasible if we retained at least $80 \%(160 / 200)$ of participants at 3 months and $64 \%(128 / 200)$ of participants at 6 months [40].

Acceptability was measured via an investigator-developed web-based survey administered at 3 months and website use. The level-specific survey asked men to assess their overall satisfaction with the program as well as each of the resources received (website, resource directory, exercise prescription, diet prescription, weekly progress report, Fitbit, text messages, diet coach, and exercise coach) as very satisfied, satisfied, neutral, dissatisfied, very dissatisfied, or did not use. To assess overall satisfaction, participants were asked "How satisfied were you with your experience with the Community of Wellness intervention and portal?" When assessing resources, participants were only asked about resources they received based on their assigned level of intervention. There was also an open text box for additional comments and feedback. The frequency of visits to the study portal was directly assessed using log-ins and web analytic data. A priori, we expected all men to log onto the website at least once and that the frequency of log-ins would increase across levels from level 1 to 4 [40]. There was a delay in activating the analytics function between August and December 2017; therefore, there were no data for the first 7 
enrollees and partial data for those enrolled between October and December 2017. Thus, summaries of web analytics data reflect an underestimate of use.

\section{Secondary Outcomes: Change and Maintenance of Diet and Physical Activity}

The intervention was designed to support the adoption or maintenance of diet and physical activity habits previously reported to be associated with reducing the risk of prostate cancer recurrence or mortality. Thus, we estimated the effect of the intervention levels on changes in self-reported diet and physical activity as secondary outcomes.

\section{Diet Assessment}

We used a validated FFQ to assess the usual diet at the time of enrollment and 3 and 6 months after the enrollment [43]. The FFQ asked men to report their usual intake of approximately 140 foods and beverages over the past 3 months, with up to nine frequency options ranging from never or $<1$ per month to $\geq 6$ per day. Cruciferous vegetables included a half cup of broccoli, cauliflower, cabbage, brussels sprouts, kale, mustard greens, or chard. Vegetable fat included avocado (half cup), oil dressing (1-2 tbs), peanut butter (1 tbs), peanuts ( $1 \mathrm{oz})$, walnuts $(1 \mathrm{oz})$, and other nuts $(1 \mathrm{oz})$. Cooked tomatoes included intake of tomato sauce (half cup), salsa (quarter cup), and pizza (2 slices). Fish included tuna fish (3-4 oz), fish sticks (1 serving), dark meat fish (eg, mackerel, salmon, sardines, bluefish, swordfish; 3-5 oz), and other fish (3-5 oz). Processed meat included intake of beef or chicken hotdogs (1 hotdog), bacon (2 slices), processed meat sandwiches (eg, salami, bologna), and other processed meat (eg, sausage, kielbasa; 2 oz or 2 small links). Consumption of whole milk was assessed by asking men how frequently they consumed 1 glass $(8 \mathrm{oz})$ of whole milk. Consumption of poultry with skin was assessed by asking men how frequently they consumed 3 to $4 \mathrm{oz}$ of chicken or turkey with skin. FFQs with $>70$ items blank were considered incomplete ( 31 participants at 3 months and 36 participants at 6 months); these data were not included in secondary analyses examining dietary change.

\section{Physical Activity Assessment}

We used the CHAMPS survey to quantify 3 types of physical activities: aerobic, strength training, and stretching. Aerobic activity included minutes per week (min/wk) of moderate-to-vigorous aerobic activities, including tennis, skating (ice, roller, or inline), jogging or running, walking or hiking uphill, walking fast for exercise, riding bikes, aerobic machines (eg, rowing, step), swimming, water exercises, aerobics or dancing, and sports (eg, basketball, soccer, racquetball). We calculated the number of sessions and total time per week spent doing strengthening activities and the number of weekly stretching sessions, as reported in the CHAMPS survey [42]. If a participant responded to at least one item on the CHAMPS survey, items that were skipped were assumed to be zero. If a participant did not respond to any question, his physical activity was missing for that time point ( 3 men at baseline, 49 men at 3 months, and 57 men at 6 months).

\section{Total Lifestyle Behavior Score}

To combine diet and physical activity into one measure, we developed a total lifestyle behavior score [40]. Multimedia Appendix 1 lists the items and points assigned to calculate the score. Men were given points for each component: 0 (not meeting recommendation), 1 (almost meeting recommendation), or 2 (meeting recommendation). Scores were summed across components to develop a diet score ranging from 0 to 14, with 14 assigned to men fully meeting dietary recommendations; a physical activity score ranging from 0 to 6 , with 6 assigned to men fully meeting the physical activity recommendations; and an overall lifestyle score ranging from 0 to 20 , with a score of 20 assigned to men fully meeting all lifestyle recommendations. One recommendation (ie, only taking supplements that have been reviewed with a health professional) was unable to be included in the score [40], as the question was inadvertently omitted from the 3-month survey following a switch in the technology platform after the initial 20 participants.

\section{Statistical Analysis}

Descriptive statistics, including proportions for categorical variables and median (IQR) for continuous variables, were used to summarize the characteristics of the participants, overall and by level of intervention received. We also used descriptive statistics to describe responses to the acceptability survey. Two participants originally randomized to level 1 and level 2 were incorrectly provided access to the level 3 intervention. In our primary acceptability and feasibility analyses, we analyzed these individuals based on intervention received (level 3), as acceptability surveys and web analytics were specific to level received. To compute participation proportions and secondary analyses of behavior change and AEs, the men were analyzed using the original randomization level (level 1 and level 2).

To explore diet and physical activity behaviors, we calculated the median (IQR) dietary score, physical activity score, and total lifestyle behavior score at each time point. Summary statistics for each component of diet and physical activity scores per arm of the study at each time point were also reported. We used $t$ tests to calculate the mean change and 95\% CI between baseline and 3 months and baseline and 6 months for each of the scores, within and between arms. As these were secondary analyses, we used a complete case approach and described levels of diet and physical activity at each time point among participants with available data.

In a posthoc sensitivity analysis, we also examined aerobic activity at each time point by level and aerobic physical activity at enrollment. We hypothesized that men with low levels of physical activity at enrollment would increase their activity at 3 months, whereas there would be no change among men who were already performing the recommended 150 minutes per week of physical activity.

Analyses were performed using Stata version 16.0 (StataCorp LP). As specified in our protocol, we tested for differences in change in the 3 behavior scores across arms using the standard $\alpha$ level of .05 to assess statistical significance. For the rest of our analyses, we adhered to the Consolidated Standards of 
Reporting Trials recommendation for pilot and feasibility studies and report descriptive statistics only [44].

\section{Results}

\section{Recruitment and Retention}

A total of 6406 men received a letter, between July 2017 and September 2018, detailing the study and providing contact information for those who wanted to learn more (Figure 1). Of these, 292 men expressed interest, 240 were screened for eligibility, and 220 were interested and deemed eligible. The main reason for ineligibility was not receiving medical clearance (13 men). Furthermore, 1 man did not own a computer and 6 declined to participate after screening. Of the 220 interested and eligible men, 202 were randomized and provided access to the web-based consenting process and surveys. These 202 men comprise the initial population for analysis.

The 202 men with prostate cancer were randomized (1:1:1:1) to increasing levels of web-based behavioral support; 49 were assigned to level 1, 51 were assigned to level 2, 50 were assigned to level 3, and 52 were assigned to level 4 (Figure 1). Of the 202 randomized men, 161 completed the onboarding process and were exposed to the intervention. Of these men, 160 were exposed to their randomly assigned intervention (38 in level 1, 38 in level 2, 42 in level 3, and 42 in level 4). As noted above, 2 men were incorrectly given access to level 3 , when originally assigned to levels 1 and 2; only one of these men (originally assigned to level 2) initiated the intervention by accessing the study website. Throughout the 6-month follow-up, 11 men withdrew after randomization; the primary reason for withdrawal was the time commitment. Withdrawal was similar across groups; 2 men withdrew in level 1, 2 men withdrew in level 2, 4 men withdrew in level 3, and 3 men withdrew in level 4.

Overall, $82.7 \%(167 / 202)$ and $77.2 \%(156 / 202)$ of men completed surveys after 3 and 6 months, respectively. By level, the 3- and 6-month follow-up proportions were $80 \%$ (39/49) and $78 \%(38 / 49)$ for level $1,84 \%(43 / 51)$ and $78 \%(40 / 51)$ for level $2,86 \%(43 / 50)$ and $76 \%(38 / 50)$ for level 3 , and $81 \%$ $(42 / 52)$ and $77 \%(40 / 52)$ for level 4 (Figure 1). 
Figure 1. Consolidated Standards of Reporting Trials (CONSORT) diagram showing the flow of participants from screening through end of study. MD: medical doctor; OHSU: Oregon Health and Sciences University; UC Denver: University of Colorado Denver; UCSF: University of California San Francisco.

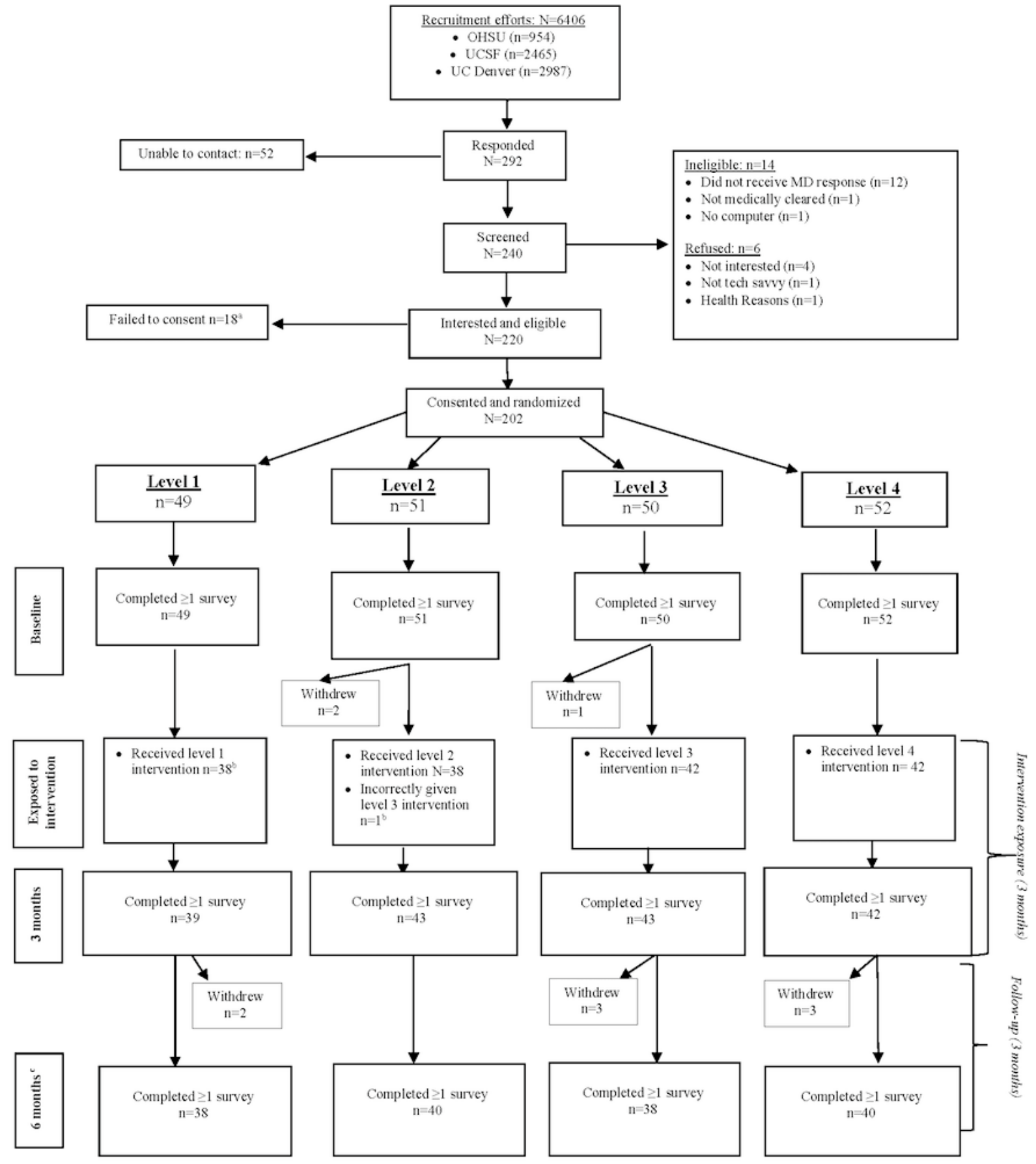

"Three of the 18 excluded individuals completed surveys and were randomized and provided access to the intervention before noting that they did not complete online consent; they were subsequently withdrawn from the study population. ${ }^{b} \mathrm{Men}$ completed an online onboarding process to receive access to the intervention. Two men (one randomized to Level 1 and one randomized to Level 2) completed onboarding but were incorrectly given access to the Level 3 intervention; of these, the level 1 man never accessed the intervention and the level 2 man accessed the level 3 intervention. "Completing the $6 \mathrm{~m}$ survey was not dependent on completing the $3 \mathrm{~m}$ survey.

\section{Characteristics of the Study Population}

Of the 202 randomized participants, the men were predominantly White (187/202, 92.6\%), well-educated (167/202, 82.7\%, reported a 4-year college degree or more), and married or had a partner (185/202, 91.6\%; Table 1). The median (IQR) age at enrollment was 70 years (65-75 years) and the median BMI was $27 \mathrm{~kg} / \mathrm{m}^{2}\left(25-29 \mathrm{~kg} / \mathrm{m}^{2}\right)$. Participants self-reported a wide

spectrum of prostate cancer stages and grades. The median (IQR) prostate-specific antigen at diagnosis was $6 \mathrm{ng} / \mathrm{ml}(5-10$ $\mathrm{ng} / \mathrm{ml}), 13.9 \%$ (28/202) reported T3 disease, and 5.9\% (12/202) reported T4 disease; 39.6\% (80/202) had intermediate grade (Gleason sum 7) and 22.8\% (46/202) had high grade (Gleason sum 8-10) cancer. Most participants reported that they had been treated for localized disease at the time of enrollment or were on active surveillance. The characteristics of the men assigned to each of the 4 levels were similar. 
Table 1. Baseline self-reported sociodemographic and clinical characteristics of 202 men with prostate cancer participating in a technology-supported physical activity and dietary intervention, overall and by level randomized.

\begin{tabular}{|c|c|c|c|c|c|}
\hline Characteristics $^{\mathrm{a}}$ & Level 1 & Level 2 & Level 3 & Level 4 & Total \\
\hline Number of men, $\mathrm{n}(\%)$ & $49(24.3)$ & $51(25.2)$ & $50(24.8)$ & $52(25.7)$ & $202(100.0)$ \\
\hline Age (years), median (IQR) & $70(64-76)$ & $70(64-75)$ & $70(64-75)$ & $70(65-74)$ & $70(65-75)$ \\
\hline BMI $\left(\mathrm{kg} / \mathrm{m}^{2}\right)$, median (IQR) & $25(23-28)$ & $28(26-30)$ & $26(24-29)$ & $27(25-29)$ & $27(25-29)$ \\
\hline \multicolumn{6}{|l|}{ Race, $n(\%)$} \\
\hline White & $44(90)$ & $45(88)$ & $48(96)$ & $50(96)$ & $187(92.6)$ \\
\hline Black & $2(4)$ & $3(6)$ & $0(0)$ & $0(0)$ & $5(2.5)$ \\
\hline Other & $0(0)$ & $1(2)$ & $0(0)$ & $0(0)$ & $1(0.5)$ \\
\hline Asian & $1(2)$ & $0(0)$ & $0(0)$ & $1(2)$ & $2(1.0)$ \\
\hline More than one race & $2(4)$ & $2(4)$ & $0(0)$ & $1(2)$ & $5(2.5)$ \\
\hline Decline to answer & $0(0)$ & $0(0)$ & $2(4)$ & $0(0)$ & $2(1.0)$ \\
\hline \multicolumn{6}{|l|}{ Education, $\mathbf{n}(\%)$} \\
\hline Grade school & $0(0)$ & $1(2)$ & $0(0)$ & $0(0)$ & $1(0.5)$ \\
\hline High school & $4(8)$ & $6(12)$ & $1(2)$ & $3(6)$ & $14(6.9)$ \\
\hline 2-year college & $9(18)$ & $4(8)$ & $2(4)$ & $5(10)$ & $20(9.9)$ \\
\hline 4-year college & $10(20)$ & $14(27)$ & $20(40)$ & $14(27)$ & $58(28.7)$ \\
\hline Graduate or professional degree & $26(53)$ & $26(51)$ & $27(54)$ & $30(58)$ & $109(54.0)$ \\
\hline \multicolumn{6}{|l|}{ Employment, n (\%) } \\
\hline Decline to answer & $0(0)$ & $0(0)$ & $0(0)$ & $1(2)$ & $1(0.5)$ \\
\hline Full time & $12(24)$ & $11(22)$ & $17(34)$ & $10(19)$ & $50(24.8)$ \\
\hline Part time & $6(12)$ & $2(4)$ & $5(10)$ & $8(15)$ & $21(10.4)$ \\
\hline Retired & $31(63)$ & $37(73)$ & $27(54)$ & $31(60)$ & $126(62.4)$ \\
\hline Disabled & $0(0)$ & $0(0)$ & $0(0)$ & $1(2)$ & $1(0.5)$ \\
\hline Unemployed & $0(0)$ & $1(2)$ & $1(2)$ & $1(2)$ & $3(1.5)$ \\
\hline \multicolumn{6}{|l|}{ Marital status, n (\%) } \\
\hline Married or partnered & $46(94)$ & $46(90)$ & $46(92)$ & $47(90)$ & $185(91.6)$ \\
\hline Divorced or separated & $1(2)$ & $1(2)$ & $1(2)$ & $3(6)$ & $6(3.0)$ \\
\hline Widowed & $1(2)$ & $2(4)$ & $2(4)$ & $0(0)$ & $5(2.5)$ \\
\hline Never married & $0(0)$ & $2(4)$ & $1(2)$ & $2(4)$ & $5(2.5)$ \\
\hline Decline to answer & $1(2)$ & $0(0)$ & $0(0)$ & $0(0)$ & $1(0.5)$ \\
\hline $\mathrm{PSA}^{\mathrm{b}}$ at $\mathrm{Dx}^{\mathrm{c}}(\mathrm{ng} / \mathrm{ml})$, median (IQR) & $5(4-10)$ & $7(5-11)$ & $7(5-10)$ & $6(5-12)$ & $6(5-10)$ \\
\hline \multicolumn{6}{|l|}{ T-stage $^{d}$, n (\%) } \\
\hline $\mathrm{T} 1$ & $15(31)$ & $15(30)$ & $13(26)$ & $19(37)$ & $62(30.7)$ \\
\hline $\mathrm{T} 2$ & $25(51)$ & $19(38)$ & $29(58)$ & $14(27)$ & $87(43.1)$ \\
\hline $\mathrm{T} 3$ & $5(10)$ & $12(24)$ & $5(10)$ & $6(12)$ & $28(13.9)$ \\
\hline $\mathrm{T} 4$ & $1(2)$ & $2(4)$ & $3(6)$ & $6(12)$ & $12(5.9)$ \\
\hline Unknown & $3(6)$ & $2(4)$ & $0(0)$ & $7(13)$ & $12(5.9)$ \\
\hline \multicolumn{6}{|l|}{ Gleason sum at Dx, n (\%) } \\
\hline 5 , low grade & $0(0)$ & $0(0)$ & $1(2)$ & $3(6)$ & $4(2.0)$ \\
\hline 6 , low grade & $6(12)$ & $7(14)$ & $13(26)$ & $8(15)$ & $34(16.8)$ \\
\hline $3+4$, intermediate grade & $16(33)$ & $5(10)$ & $10(20)$ & $10(19)$ & $41(20.3)$ \\
\hline
\end{tabular}




\begin{tabular}{|c|c|c|c|c|c|}
\hline Characteristics $^{\mathrm{a}}$ & Level 1 & Level 2 & Level 3 & Level 4 & Total \\
\hline $4+3$, intermediate grade & $10(20)$ & $12(24)$ & $11(22)$ & $6(12)$ & $39(19.3)$ \\
\hline $8-10$, high grade & $8(16)$ & $14(28)$ & $12(24)$ & $12(23)$ & $46(22.8)$ \\
\hline Unknown or Do not know & $9(18)$ & $12(24)$ & $3(6)$ & $13(25)$ & $37(18.3)$ \\
\hline \multicolumn{6}{|l|}{ Disease status at enrollment $^{\mathrm{e}}, \mathrm{n}(\%)$} \\
\hline On active surveillance, PSA low or not-rising & $3(6)$ & $7(14)$ & $3(6)$ & $6(12)$ & $19(9.4)$ \\
\hline On active surveillance, PSA elevated or rising & $1(2)$ & $2(4)$ & $5(10)$ & $4(8)$ & $12(5.9)$ \\
\hline $\begin{array}{l}\text { Completed treatment for localized disease, PSA low or } \\
\text { undetectable }\end{array}$ & $31(63)$ & $23(45)$ & $26(52)$ & $27(52)$ & $107(53.0)$ \\
\hline Completed treatment for localized disease, PSA elevated & $3(6)$ & $1(2)$ & $4(8)$ & $2(4)$ & $10(5.0)$ \\
\hline Cancer spread locally & $1(2)$ & $2(4)$ & $1(2)$ & $3(6)$ & $7(3.5)$ \\
\hline Metastatic disease & $2(4)$ & $5(10)$ & $4(8)$ & $3(6)$ & $14(6.9)$ \\
\hline Other or Do not know & $8(16)$ & $11(22)$ & $7(14)$ & $7(13)$ & $33(16.3)$ \\
\hline Time since Dx (years) ${ }^{\mathrm{f}}$, median (IQR) & $9(4-14)$ & $4(2-7)$ & $3(2-10)$ & $4(2-9)$ & $4(2-10)$ \\
\hline Time since first treatment (years), median (IQR) & $2(1-9)$ & $4(2-10)$ & $3(1-11)$ & $3(1-6)$ & $3(1-9)$ \\
\hline \multicolumn{6}{|l|}{ Enrollment site, n (\%) } \\
\hline Oregon $\left(\mathrm{OHSU}^{\mathrm{g}}\right)$ & $21(43)$ & $23(45)$ & $15(30)$ & $18(35)$ & $77(38.1)$ \\
\hline California $\left(\mathrm{UCSF}^{\mathrm{h}}\right)$ & $16(33)$ & $14(27)$ & $19(38)$ & $19(37)$ & 68 (33.7) \\
\hline Colorado (UCD $\left.{ }^{\mathrm{i}}\right)$ & $12(24)$ & $14(27)$ & $16(32)$ & $15(29)$ & $57(28.2)$ \\
\hline
\end{tabular}

${ }^{\mathrm{a}}$ Percentages may not sum to $100 \%$ due to rounding.

${ }^{\mathrm{b}} \mathrm{PSA}$ : prostate-specific antigen.

${ }^{\mathrm{c}} \mathrm{Dx}$ : diagnosis.

${ }^{\mathrm{d}}$ T-Stage: Tumor (T) component of the TNM staging system developed by the American Joint Committee on Cancer.

${ }^{\text {e}}$ Self-reported disease status.

${ }^{\mathrm{f}}$ Diagnosis date was known for 127 men (31, 30, 32, 34 in levels 1-4), and the first treatment date was known for 135 men (26, 34, 39, 36 in levels 1-4). ${ }^{\mathrm{g}} \mathrm{OHSU}$ : Oregon Health Sciences University.

${ }^{\mathrm{U}} \mathrm{UCSF}$ : University of California San Francisco.

${ }^{\mathrm{i}}$ UCD: University of Colorado Denver.

\section{Acceptability of Intervention}

As hypothesized, engagement and satisfaction with the intervention increased across levels (Table 2). On the basis of web analytics data on 154 of 161 men exposed to the intervention, the median (IQR) number of days that participants went to the study website over the 3-month intervention was 2 (IQR 1-3) in level 1, 9 (IQR 5-13) in level 2, 11 (IQR 8-16) in level 3, and 16 (IQR 10-19) in level 4. The most commonly visited pages for men in levels 2 to 4 were the main home page/dashboard and the follow-up survey page where participants could self-report progress toward their diet and exercise goals. Although all other pages were visited at least once, the median number of days that participants visited the remaining pages was low (1-5 visits each). 
Table 2. Acceptability of a 3-month technology-supported behavioral intervention for men with prostate cancer by level of intervention received.

\begin{tabular}{lllll}
\hline Characteristics $^{\mathrm{a}}$ & Level 1 & Level 2 & Level 3 & Level 4 \\
\hline Number of men $^{\mathrm{b}}$ & 39 & 42 & 44 & 42 \\
Frequency of portal visits (days), median (IQR) $^{\mathrm{b}}$ & $2(1-3)$ & $9(5-13)$ & $11(8-16)$ & $16(10-19)$
\end{tabular}

Overall satisfaction with Community of Wellness intervention and portal, $\mathbf{n}(\%)$

Very satisfied
Satisfied
Neutral
Dissatisfied
Very dissatisfied
Did not report

Resource directory, $\mathbf{n}(\%)$

Excellent

Very good

Good

Average

Poor

Did not use

Did not report

Exercise prescription, $\mathrm{n}(\%)$

Excellent

Very good

Good

Average

Poor

Did not use

Did not report

Diet prescription, n (\%)

Excellent
Very good
Good
Average
Poor
Did not use

Did not report

\section{Weekly progress report, n (\%)}

Excellent

Very good

Good

Average

Poor

Did not use

Did not report

$\begin{array}{llll}4(10) & 5(12) & 5(11) & 10(24) \\ 16(41) & 22(52) & 18(41) & 17(40) \\ 10(26) & 11(26) & 15(34) & 11(26) \\ 4(10) & 1(2) & 2(5) & 1(2) \\ 1(3) & 0(0) & 1(2) & 1(2) \\ 4(10) & 3(7) & 3(7) & 2(5)\end{array}$

$\begin{array}{llll}1(3) & 2(5) & 0(0) & 4(10) \\ 5(13) & 9(21) & 4(9) & 6(14) \\ 12(31) & 9(21) & 14(32) & 8(19) \\ 3(8) & 3(7) & 5(11) & 7(17) \\ 0(0) & 2(5) & 0(0) & 3(7) \\ 13(33) & 12(29) & 18(41) & 10(24) \\ 5(13) & 5(12) & 3(7) & 4(10)\end{array}$

$-$

-

$-$

$-$

-

-

-

$-$

-

-

-

-

-

$-$

$-$

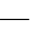

-

-

-

$-$

-

-

$-$
1 (2)

$3(7)$

$6(14)$

19 (43)

6 (14)

$0(0)$

6 (14)

4 (9)

8 (19)

2(5)

6 (14)

11 (25)

12 (27)

12 (29)

5 (12)

3 (7)

2 (5)

$6(14)$

4 (9)

3 (7)

12 (27)

14 (32)

7 (16)

1 (2)

3 (7)

4 (9)

8 (19)

$10(24)$

10 (24)

10 (24)

5 (12)

1 (2)

4 (10)

2 (5)

12 (29)

12 (29)

4 (10)

8 (19)

$0(0)$

3 (7)

3 (7)

$11(26)$

$13(31)$

$6(14)$

6 (14)

1 (2)

2 (5)

3 (7) 


\begin{tabular}{|c|c|c|c|c|}
\hline Characteristics $^{\mathrm{a}}$ & Level 1 & Level 2 & Level 3 & Level 4 \\
\hline \multicolumn{5}{|l|}{ Fitbit, n (\%) } \\
\hline Excellent & - & - & $9(20)$ & $6(14)$ \\
\hline Very good & - & - & $5(11)$ & $8(19)$ \\
\hline Good & - & - & $7(16)$ & $7(17)$ \\
\hline Average & - & - & $3(7)$ & $1(2)$ \\
\hline Poor & - & - & $8(18)$ & $4(10)$ \\
\hline Did not use & - & - & $7(16)$ & $12(29)$ \\
\hline Did not report & - & - & $5(11)$ & $4(10)$ \\
\hline \multicolumn{5}{|c|}{ Text messages, n (\%) } \\
\hline Excellent & - & - & $0(0)$ & $4(10)$ \\
\hline Very good & - & - & $4(9)$ & $8(19)$ \\
\hline Good & - & - & $14(32)$ & $8(19)$ \\
\hline Average & - & - & $10(23)$ & $2(5)$ \\
\hline Poor & - & - & $1(2)$ & $5(12)$ \\
\hline Did not use & - & - & $10(23)$ & $11(26)$ \\
\hline Did not report & - & - & $5(11)$ & $4(10)$ \\
\hline \multicolumn{5}{|l|}{ Diet coach, n (\%) } \\
\hline Excellent & - & - & - & $9(21)$ \\
\hline Very good & - & - & - & $9(21)$ \\
\hline Good & - & - & - & $6(14)$ \\
\hline Average & - & - & - & $6(14)$ \\
\hline Poor & - & - & - & $1(2)$ \\
\hline Did not use & - & - & - & $7(17)$ \\
\hline Did not report & - & - & - & $4(10)$ \\
\hline \multicolumn{5}{|c|}{ Exercise coach, n (\%) } \\
\hline Excellent & - & - & - & $8(19)$ \\
\hline Very good & - & - & - & $9(21)$ \\
\hline Good & - & - & - & $6(14)$ \\
\hline Average & - & - & - & $7(17)$ \\
\hline Poor & - & - & - & $2(5)$ \\
\hline Did not use & - & - & - & $6(14)$ \\
\hline Did not report & - & - & - & $4(10)$ \\
\hline
\end{tabular}

${ }^{\mathrm{a}}$ Percentages may not sum to $100 \%$ due to rounding.

${ }^{b}$ Web analytics data were available for 154 (33, 38, 41, and 42 for levels $1,2,3$, and 4, respectively) of 161 men exposed to the intervention. The acceptability survey was sent after the 3-month intervention period; because of technical errors, 44 men received the acceptability survey late.

${ }^{\mathrm{c}}$ Empty cells denote intervention features that were not offered to a given level; participants were not asked to provide feedback on features they did not receive.

A higher proportion of men $(10 / 42,24 \%)$ in level 4 reported that they were very satisfied with the intervention than men in levels 1,2 , and $3(4 / 39,10 \% ; 5 / 42,12 \%$; and 5/44, $11 \%$, respectively). A total of 6 men in levels 1 to 3 ( 1 in level 1, 4 in level 2, and 1 in level 3) who completed surveys at 3 months had not accessed the study website intervention (Figure 1), which may in part reflect lower satisfaction scores for these levels compared with level 4 . In addition, a higher proportion of men in level 1 reported that they were dissatisfied or very dissatisfied with the intervention $(5 / 39,13 \%)$ compared with levels 2,3 , and $4(1 / 42,2 \% ; 3 / 44,7 \%$; and $2 / 42,5 \%$, respectively). Men in level $4(n=42)$ were also more likely to rate the intervention features as excellent or very good: exercise prescription (20/42, 48\%), diet prescription $(24 / 42,57 \%)$, and weekly progress report $(24 / 42,57 \%)$ compared with the 42 men in level $2(12 / 42,29 \% ; 13 / 42,31 \% ; 17 / 42,40 \%$, respectively), 
and 44 men in level $3(9 / 44,20 \% ; 17 / 44,39 \% ; 15 / 44,34 \%)$. In contrast to our expectations, a large number of men in levels 3 and 4 reported that they did not like $(8 / 44,18 \%$ and $4 / 42,10 \%$, respectively) or did not use (7/44, 16\% and 12/42, 29\%, respectively) the Fitbit. Approximately one-fourth of the men in levels 3 and 4 reported that they did not use the text messages $(10 / 44,23 \%$ in level 3 and 11/42, 26\% in level 4). Of the 42 men in level 4, 26 (62\%) completed an exercise coaching call ( 8 were unable to be contacted and 8 declined) and 35 (83\%) completed a diet coaching call ( 2 were unable to be contacted and 5 declined). Of the men who received the calls, $88 \%$ (23/26) rated the exercise call as good to excellent and 69\% (24/35) rated the diet call as good to excellent.

Participants' open-ended feedback on the intervention is provided in Multimedia Appendix 2. Participants noted challenges with the onboarding process, insufficient personalization of the study materials, and limited information tailored to their level and readiness for change. Although the intervention provided personalized diet and exercise prescriptions based on baseline surveys (levels 2-4), feedback from the open-ended comments indicated that several participants desired more interactive feedback, direction, and reminders. As noted above, many men indicated that they did not like or use the Fitbit; some participants already owned other devices and would have preferred to have the option to integrate those into the study website.

\section{Lifestyle Behavior}

Figure 2 shows the between-group difference in mean change (95\% CI) from enrollment to 3 months comparing with the 4 levels for the overall lifestyle score. Changes between levels 2 ,
3 , and 4 versus level 1 for the diet and physical activity scores and their subcomponents are shown in Figure 3 and Figure 4. The between-group differences in mean change, comparing each level to level 1, were as follows: 0.93 (95\% CI 0.44-1.41) points for level 2; 0.51 (95\% CI 0.02-0.99) points for level 3; and 1.11 (95\% CI 0.65-1.57) points for level 4. The median (IQR) values for the lifestyle score and its components, by study arm and time point, are shown in Multimedia Appendix 3 and the between-group differences in mean change from enrollment to 6 months are shown in Multimedia Appendices 4-6. The small improvement in score for level 4 was attenuated, but still present, at 6 months (between-group difference in mean change level 4 vs 1: 0.72 ; $95 \%$ CI 0.26-1.18 points).

Level 4 had a greater improvement in diet scores at 3 months compared with level 1 (Figure 3). The between-group difference in mean change from enrollment to month 3 in level 4 as compared with level 1 was 0.49 (IQR 0.22-0.77) points. This change seemed to be driven by an increased intake of cruciferous vegetables and healthy vegetable fat and decreased intake of processed meat. As with the overall lifestyle score, the improvement was present, but attenuated, at 6 months (between-group difference in mean change in level 4 vs level 1: 0.32 [IQR 0.09-0.54]; Multimedia Appendix 5).

Similarly, for physical activity, only level 4 appeared to have a greater increase in physical activity at 3 months compared with level 1 (between-group difference in mean: 0.39; 95\% CI 0.08-0.69 points; Figure 4$)$. The change appeared to be due to small increases in aerobic exercise, strength training, and stretching. However, the difference in mean change for the overall score was not maintained at 6 months (Multimedia Appendix 6).

Figure 2. Difference in mean change in an overall lifestyle score (range 0-20) from baseline to 3 months, comparing intervention levels 2 to 4 with level 1. Higher scores indicate more healthy lifestyle behaviors. These secondary analyses included the 146 men with complete data on lifestyle behaviors at 0 and 3 months.

\begin{tabular}{|c|c|}
\hline Comparison & $\begin{array}{c}\text { Difference in } \\
\text { means }[95 \% \mathrm{CI}]\end{array}$ \\
\hline Level 2 versus 1 & $0.93[0.44-1.42]$ \\
\hline Level 3 versus 1 & $0.51[0.02-0.99]$ \\
\hline \multirow[t]{3}{*}{ Level 4 versus 1} & $1.11[0.65-1.57]$ \\
\hline & $0.86[0.51-1.21]$ \\
\hline & \\
\hline
\end{tabular}


Figure 3. Differences in mean change in an overall diet score (range 0-14) and servings per day of diet items from baseline to 3 months, comparing intervention levels 2 to 4 with level 1 . A higher score for the overall diet score indicates healthier diet behaviors. The intervention aimed to increase intake of cruciferous vegetables, fish, tomatoes, and vegetable fat and decrease intake of poultry with skin, processed meat, and whole milk. These secondary analyses included the 146 men with complete data on diet behaviors at 0 and 3 months.

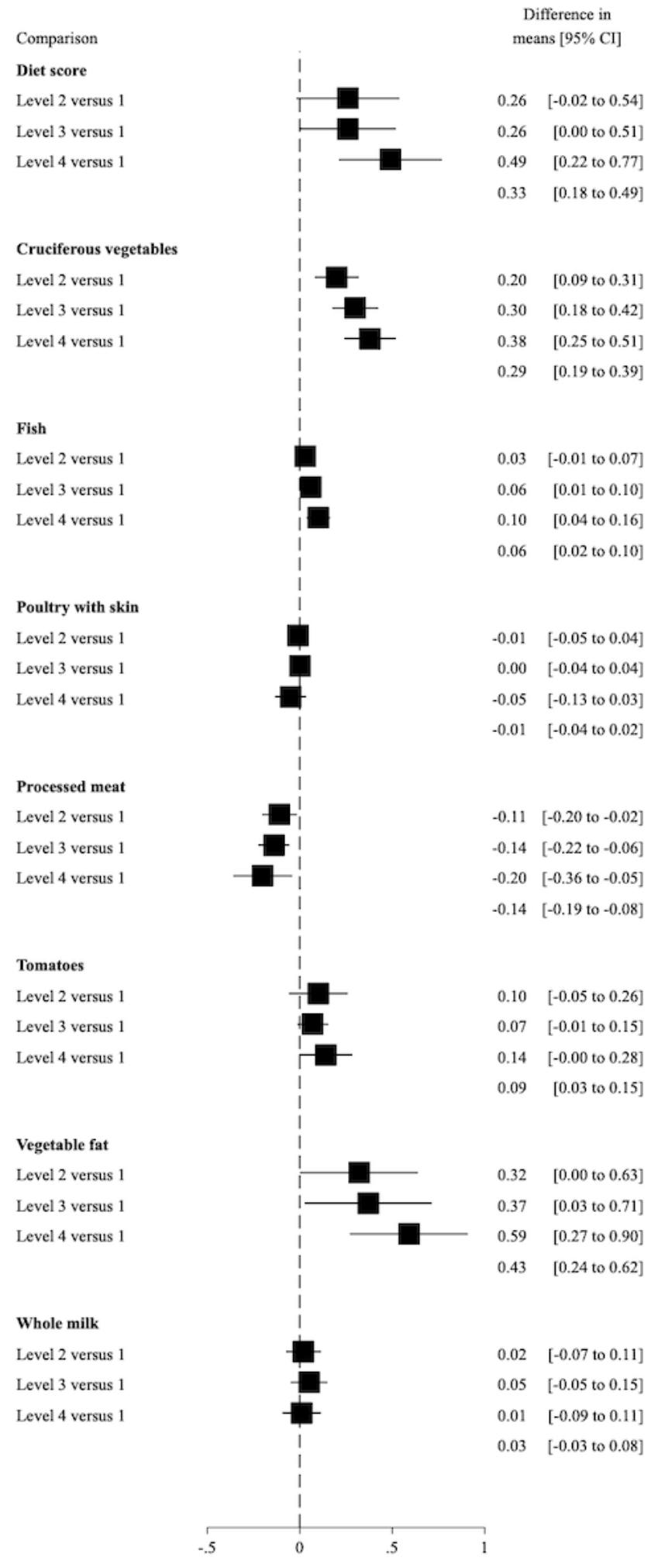


Figure 4. Difference in mean change in an overall physical activity score (range 0-6) and types of physical activity (minutes per week of aerobic; sessions per week of strength training and stretching) from baseline to 3 months, comparing intervention levels 2 to 4 with level 1 . Higher scores indicate more physical activity. These secondary analyses were performed among the 152 men with complete data on physical activity at 0 and 3 months.

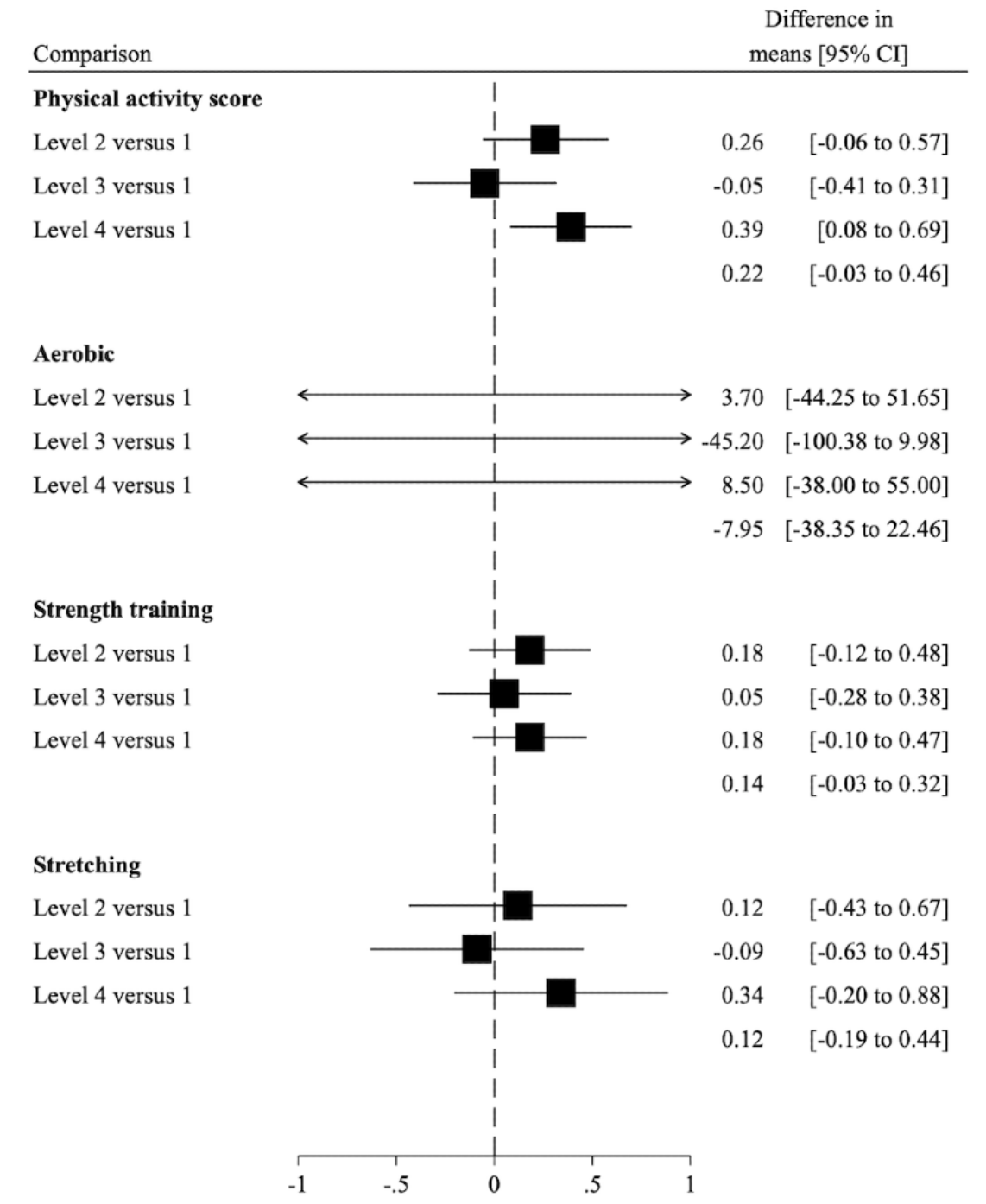

In a posthoc sensitivity analysis, we stratified men according to their self-reported aerobic activity level at the time of enrollment. As shown in Table 3, in levels 3 and 4, men who reported $<90 \mathrm{~min} /$ wk of aerobic physical activity at enrollment appeared to report more aerobic physical activity at 3 months (median change from baseline to 3 months in level 3: $60 \mathrm{~min} / \mathrm{wk}$;
IQR 30-75; level 4: $75 \mathrm{~min} / \mathrm{wk}$; IQR 30-150). Although these changes were not fully maintained, men in levels 3 and 4 who started with $<90 \mathrm{~min} / \mathrm{wk}$ of aerobic activity reported a median increase of $30 \mathrm{~min} / \mathrm{wk}$ at 6 months compared with enrollment (level 3 IQR 0-135; level 4 IQR 0-330). 
Table 3. Moderate-to-vigorous intensity aerobic physical activity minutes per week at baseline, 3 months, and 6 months among men with prostate cancer participating in a technology-supported behavioral intervention, overall and by level randomized and baseline activity.

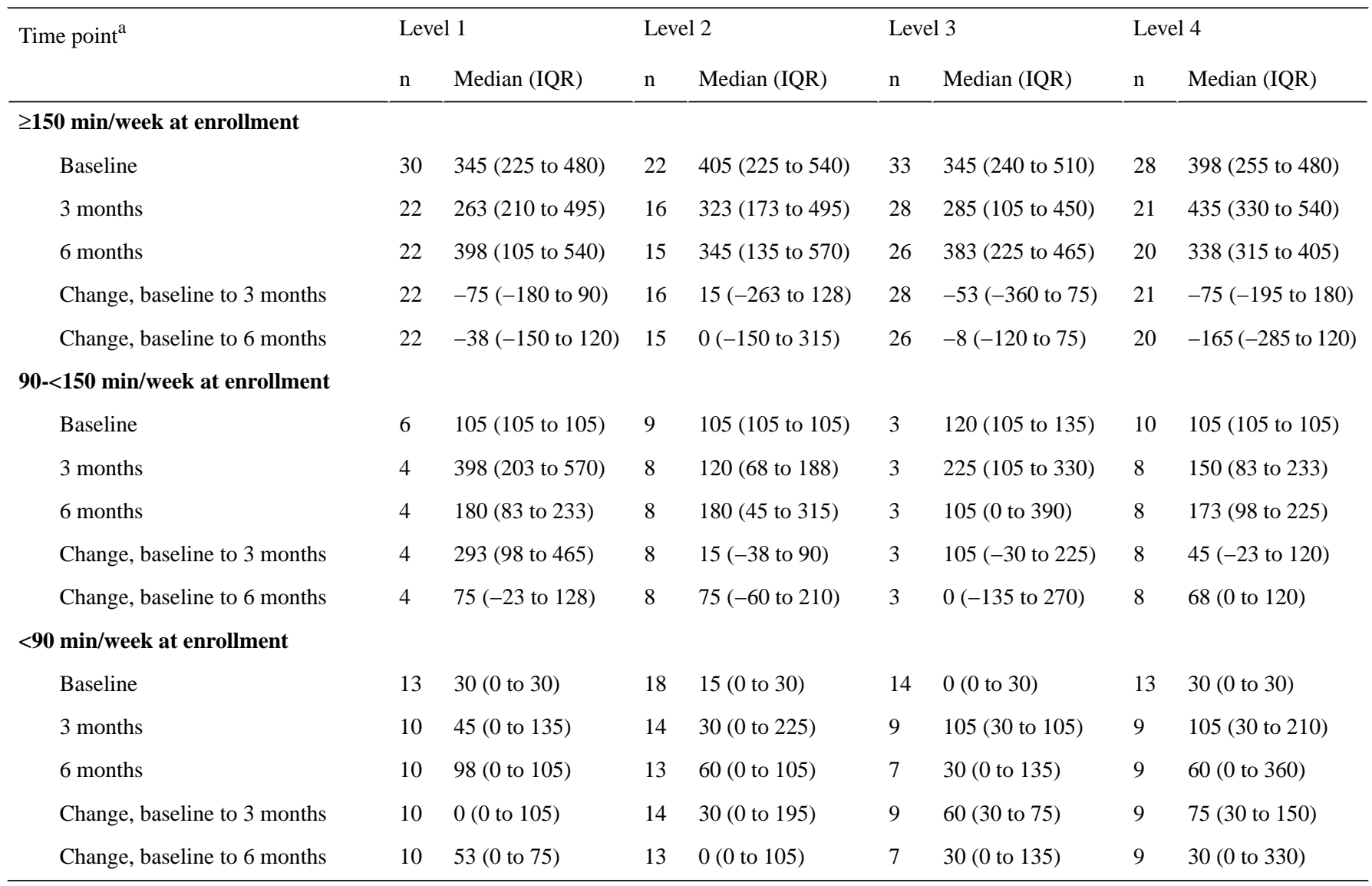

${ }^{\mathrm{a}}$ Two men in level 2 and 1 man in level 4 had unknown baseline physical activity.

\section{Nonserious Adverse Events}

No serious AEs occurred during the study. However, total nonserious AEs (study related and unrelated) were common in the older population of men with prostate cancer (Table 4). Most of the AEs $(246 / 356,69.1 \%)$ were associated with a pre-existing condition; only $15.4 \%$ (55/356) of the AEs were self-reported by the participants to be related to the study and included exacerbations of pre-existing problems. Muscle pain/injury, fatigue, and joint or bone pain were the most frequently reported, accounting for $82 \%(45 / 55)$ of study-related AEs. All study-related AEs were mild to moderate in severity. Although the number of study-related AEs was low, they did appear to increase across levels, particularly going from level 1 (8 study-related AEs) to level 2 (14 study-related AEs). The difference in study-related AEs across levels was driven by higher reports of muscle pain/injury and fatigue in higher levels. For example, there were 7 reports of muscle pain/injury that were deemed study related by participants in levels 3 and 4, 6 in level 2, and 3 in level 1. Study-related fatigue was highest in level 4 , reported 6 times, compared with 2 reports of fatigue in level 1 and 1 report of fatigue in levels 2 and 3 each. 
Table 4. Nonserious adverse events self-reported at 3 months among men with prostate cancer participating in a technology-supported behavioral intervention by randomized level.

\begin{tabular}{llllll}
\hline Nonserious AEs $^{\mathrm{a}}$ & Level 1 & Level 2 & Level 3 & Level 4 & Total \\
\hline Total AE, $\mathrm{n}$ & 80 & 133 & 76 & 67 & 356 \\
AE related to pre-existing conditions, $\mathrm{n}$ & 53 & 91 & 54 & 48 & 246 \\
Study-related AE, $\mathrm{n}$ & 8 & 14 & 15 & 18 & 55
\end{tabular}

\section{Specific AEs, $\mathbf{n}$}

\section{Joint or bone pain}

Any

Pre-existing

Study related

Muscle pain or injury

Any

Pre-existing

Study related

\section{Gastrointestinal issues}

Any

Pre-existing

Study related

\section{Fatigue}

Any

Pre-existing

Study related

Dizziness or vertigo

Any

Pre-existing

Study related

Shortness of breath

Any

Pre-existing

Study related

Cardiovascular event

Any

Pre-existing

Study related
21

16

1

20

9

3

14

11

2

14

9

2

\section{9}

6

0

\section{1}

1

0

40
31
5

$$
24
$$

105

5

20

15

82

5

1

12

29

17

\section{4}

15

88

6

14

9

49

$\begin{array}{llll}6 & 7 & 7 & 23\end{array}$

15

15

12

1

8

.

$\begin{array}{llll}8 & & \\ 8 & 11 & 48\end{array}$

1

5

9

48

5

37

8

$3 \quad 8$

$\begin{array}{lllll}14 & 24 & 10 & 16 & 64 \\ 9 & 17 & 10 & 11 & 47 \\ 2 & 1 & 1 & 6 & 10\end{array}$


from a person. A high proportion of men reported difficulty registering on the portal website, and a quarter of the men failed to complete the process and did not end up receiving their assigned intervention. This underscores the need for additional orientation, email reminders, and/or follow-up calls to ensure that participants have sufficient technical support to access web-based resources. Future studies need to address how to collect sufficient personal information to deliver a tailored intervention without overburdening participants and preventing them from continuing in the program. In addition, individuals who received two 30-minute coach calls (level 4) were more satisfied with the intervention compared with other groups and appeared to be more successful in making small lifestyle changes. These results suggest that some level of coaching or human interaction is important for participant satisfaction with remotely delivered lifestyle programs. This is in agreement with previous findings [45-47]. Additional research is needed to assess whether other technology-based interactions (eg, tailored text messages or chatbots) or web-based peer-to-peer interactions can facilitate similar satisfaction and improve behavior change outcomes as coaching calls [47-50]. Overall, future studies are challenged to identify the minimum dose of health coaching needed for participant satisfaction and meaningful behavior change while maintaining scalability. These studies should consider innovative study designs that efficiently support testing multiple intervention components (eg, multiphase optimization strategy framework) [51,52].

In secondary analyses, it appeared that the intervention had small effects on lifestyle behaviors. For example, we observed a median increase of 0.5 servings per day (IQR 0.2-0.9) in cruciferous vegetable consumption in level 4 at 3 months. The changes we observed are of similar magnitude to those reported by other studies with more intensive health coaching. The Reach Out to Enhance Wellness trial conducted among long-term breast, prostate, and colorectal cancer survivors included 15 health coaching sessions over 12 months and observed an increase in fruit and vegetable intake of 1.1 servings per day (95\% CI 0.76-1.47) when comparing the intervention group with the control group at 12 months [53]. Our results comparing the different intervention levels add to the literature and suggest that at least some higher touch coaching may be needed to successfully modify dietary intake.

Most men in the study did not increase their physical activity from the time of enrollment. Our study population, however, reported high levels of physical activity at enrollment and thus did not have much room for improvement. Indeed, when we stratified men based on whether they met the recommended amounts of physical activity at enrollment, we observed an increase in aerobic physical activity at 3 months among men not meeting the physical activity guidelines at baseline in levels 3 and 4. For example, the median (IQR) $\mathrm{min} / \mathrm{wk}$ of moderate-to-vigorous physical activity at enrollment and 3 months among inactive men in level 4 was 30 (IQR 0-30) and 105 (IQR 30-210). This change was not maintained at 6 months. Among those who had already met the recommended 150 minutes of exercise per week at the time of enrollment, there was no increase in exercise with increasing intervention levels, and among those assigned to levels 3 and 4, there appeared to be a decrease in total minutes of exercise. It is possible that very active men altered their behavior once they realized that they exceeded the guidelines. Future studies using adaptive trial designs, such as sequential multiple assignment randomized trials, to target intervention resources to participants who need them most would be of interest.

This trial was designed to evaluate the feasibility of direct-to-patient enrollment and acceptability of a remotely delivered, web-based behavioral intervention in a study population with a wide distribution of geography and clinical disease features. Our team previously reported the results of the Prostate 8-I (P8-I) pilot study conducted at UCSF. P8-I reported a larger improvement in diet than that observed in the present trial. One difference in study design that may have played a role in the different results could be the in-clinic recruitment and on-site study visits in P8-I. Given the difference in acceptability reported by men in level 4 compared with levels 1 to 3 in this study, it is possible that having a personal connection to the study helped motivate participants in P8-I to make larger dietary changes. In addition, P8-I excluded participants who had already met 4 of 8 prespecified lifestyle recommendations, whereas this pilot did not.

\section{Limitations}

There are several limitations of this study to consider and improve upon in future trials. First, individuals who volunteered for this study were predominantly White and highly educated; thus, our results may not be generalizable to all men with prostate cancer. Further work is warranted to assess whether a remotely delivered, web-based intervention is acceptable or beneficial for more diverse or underserved populations. Most participants also had localized disease; the feasibility and acceptability of lifestyle interventions in men with more advanced disease remains to be determined. Second, diet and physical activity were assessed using self-reporting, and the instruments used may not have been sufficiently discriminative to detect small changes in lifestyle behaviors. Third, we did not include the participants' caregivers or family/friends in the intervention. In our past trial of a structured partnered exercise program for prostate cancer patients and their spouses, retention and adherence rates to exercise in patients exceeded that in our other patient-only trials [9]. Therefore, partner support may be a key facilitator for patient behavior change. Improving the health of partners may also have a positive impact on patients' health, a concept we are currently testing in a clinical exercise trial for cancer survivors and their spouse (or partners; NCT03630354). Fourth, we selected one type of physical activity tracker for integration with the web portal, and several comments made in the exit survey indicated that people would prefer more options and to use the devices they already owned (see Multimedia Appendix 2 for participant feedback). Participant feedback also indicated that additional programming to personalize and update the recommendations and messaging over time was desired. Accordingly, our team is currently enrolling individuals going to surgery for prostate cancer (Prostate 8-II trial, NCT \#03999151) to a longer intervention (24 months) with more tailored feedback that adjusts to real-time self-reported diet and exercise data. P8-II also provides quarterly health coaching. Finally, it is worth noting that nonserious 
study-related AEs increased across intervention levels. However, the AEs reported were consistent with expected side effects of increased physical activity (eg, muscle pain, fatigue) and/or dietary change (eg, fatigue) and all were mild to moderate.

\section{Conclusions}

The TrueNTH Community of Wellness trial demonstrated the feasibility of a web-based, remotely delivered, tailored behavioral intervention among individuals with all stages of prostate cancer. Men in level 4 who received two 30-minute phone calls reported higher satisfaction, engaged more frequently with the intervention, and reported small improvements in diet and physical activity compared with men in level 1. Future studies are warranted to evaluate how to increase the effect of the intervention on lifestyle behaviors, while maintaining long-term sustainability and scalability, as well as designing and implementing behavioral interventions for more diverse populations.

\section{Acknowledgments}

The authors would like to acknowledge all the participants and Esther Moe, Carol-Ann Mullin, and Jade Moon for their assistance in managing and implementing the study. The authors also thank the Movember Foundation for supporting this project as part of its global TrueNTH initiative. This project was supported by the National Center for Advancing Translational Sciences, National Institutes of Health (NIH), Grant Numbers UL1 TR001872 and UL1TR002369, and other National Institutes of Health grants P30DK098722, P30 CA069533-21, and NCI K07CA197077. Its contents are solely the responsibility of the authors and do not necessarily represent the official views of the NIH. The project was also supported by the Steven and Christine Burd-Safeway Distinguished Professorship (JC) and the Helen Diller Family Chair in Population Science for Urologic Cancer (SK).

\section{Conflicts of Interest}

SK is associated with Fellow Health Inc. TB is associated with AbbVie, Alliance Foundation Trials, Arvinas Inc, Astellas, AstraZeneca, Bayer, Boehringer Ingelheim, Clovis Oncology, Corcept Therapeutics, Endocyte Inc, GlaxoSmithKline, Janssen Biotech, Janssen Japan, Janssen Research \& Development, Medivation, Inc, Merck, OncoGenex, Pfizer, Salarius Pharmaceuticals, Sotio, Theraclone Sciences/OncoResponse. JC's spouse is employed by GRAIL Inc. KP is employed by Movember. The authors are the developers/sponsors of the intervention evaluated in this report.

\section{Multimedia Appendix 1}

The components and points assigned for the lifestyle behavior score.

[DOCX File, 25 KB-Multimedia Appendix 1]

\section{Multimedia Appendix 2}

Participant feedback from a 3-month technology-supported behavioral intervention for prostate cancer survivors. [DOCX File, 27 KB-Multimedia Appendix 2]

\section{Multimedia Appendix 3}

Baseline, 3-month, 6-month, and change from baseline lifestyle, diet, and physical activity scores among men with prostate cancer participating in a 3-month technology-supported behavioral intervention, randomized by level.

[DOCX File, 32 KB-Multimedia Appendix 3]

\section{Multimedia Appendix 4}

Difference in mean change in an overall lifestyle score (range 0-20) from baseline to 6 months, comparing intervention levels 2 to 4 with level 1 . Higher scores indicate more healthy lifestyle behaviors.

[PNG File, 116 KB-Multimedia Appendix 4]

\section{Multimedia Appendix 5}

Differences in mean change in an overall diet score (range 0-14) and servings per day of diet items from baseline to 6 months, comparing intervention levels 2 to 4 with level 1. A higher score for the overall diet score indicates healthier diet behaviors. The intervention aimed to increase intake of cruciferous vegetables, fish, tomatoes, and vegetable fat and decrease intake of poultry with skin, processed meat, and whole milk.

[PNG File, 171 KB-Multimedia Appendix 5] 


\section{Multimedia Appendix 6}

Difference in mean change in an overall physical activity score (range 0-6) and types of physical activity (minutes per week of aerobic; sessions per week of strength training and stretching) from baseline to 6 months, comparing intervention levels 2 to 4 with level 1. Higher scores indicate more physical activity.

[PNG File, 452 KB-Multimedia Appendix 6]

\section{Multimedia Appendix 7}

CONSORT-eHEALTH checklist (V1.6.1).

[PDF File (Adobe PDF File), 1221 KB-Multimedia Appendix 7]

\section{References}

1. Miller KD, Nogueira L, Mariotto AB, Rowland JH, Yabroff KR, Alfano CM, et al. Cancer treatment and survivorship statistics, 2019. CA Cancer J Clin 2019 Sep;69(5):363-385 [FREE Full text] [doi: 10.3322/caac.21565] [Medline: 31184787]

2. Barry MJ, Simmons LH. Prevention of prostate cancer morbidity and mortality: primary prevention and early detection. Med Clin North Am 2017 Jul;101(4):787-806. [doi: 10.1016/j.mcna.2017.03.009] [Medline: 28577627]

3. Winters-Stone KM, Moe E, Graff JN, Dieckmann NF, Stoyles S, Borsch C, et al. Falls and frailty in prostate cancer survivors: current, past, and never users of androgen deprivation therapy. J Am Geriatr Soc 2017 Jul;65(7):1414-1419 [FREE Full text] [doi: 10.1111/jgs.14795] [Medline: 28263373]

4. Galvão DA, Taaffe DR, Spry N, Joseph D, Turner D, Newton RU. Reduced muscle strength and functional performance in men with prostate cancer undergoing androgen suppression: a comprehensive cross-sectional investigation. Prostate Cancer Prostatic Dis 2009;12(2):198-203. [doi: 10.1038/pcan.2008.51] [Medline: 18852703]

5. Chang D, Joseph DJ, Ebert MA, Galvão DA, Taaffe DR, Denham JW, et al. Effect of androgen deprivation therapy on muscle attenuation in men with prostate cancer. J Med Imaging Radiat Oncol 2014 Apr;58(2):223-228. [doi: 10.1111/1754-9485.12124] [Medline: 24118850]

6. Iadeluca L, Mardekian J, Chander P, Hopps M, Makinson GT. The burden of selected cancers in the US: health behaviors and health care resource utilization. Cancer Manag Res 2017;9:721-730 [FREE Full text] [doi: 10.2147/CMAR.S143148] [Medline: 29238222]

7. Finlay A, Wittert G, Short CE. A systematic review of physical activity-based behaviour change interventions reaching men with prostate cancer. J Cancer Surviv 2018 Aug;12(4):571-591. [doi: 10.1007/s11764-018-0694-8] [Medline: 29770953]

8. Winters-Stone KM, Dobek JC, Bennett JA, Dieckmann NF, Maddalozzo GF, Ryan CW, et al. Resistance training reduces disability in prostate cancer survivors on androgen deprivation therapy: evidence from a randomized controlled trial. Arch Phys Med Rehabil 2015 Jan;96(1):7-14 [FREE Full text] [doi: 10.1016/j.apmr.2014.08.010] [Medline: 25194450]

9. Winters-Stone KM, Lyons KS, Dobek J, Dieckmann NF, Bennett JA, Nail L, et al. Benefits of partnered strength training for prostate cancer survivors and spouses: results from a randomized controlled trial of the Exercising Together project. $\mathrm{J}$ Cancer Surviv 2016 Aug;10(4):633-644. [doi: 10.1007/s11764-015-0509-0] [Medline: 26715587]

10. Fornusek CP, Kilbreath SL. Exercise for improving bone health in women treated for stages I-III breast cancer: a systematic review and meta-analyses. J Cancer Surviv 2017 Oct;11(5):525-541. [doi: 10.1007/s11764-017-0622-3] [Medline: 28639157]

11. Winters-Stone KM, Dobek JC, Bennett JA, Maddalozzo GF, Ryan CW, Beer TM. Skeletal response to resistance and impact training in prostate cancer survivors. Med Sci Sports Exerc 2014 Aug;46(8):1482-1488 [FREE Full text] [doi: 10.1249/MSS.0000000000000265] [Medline: 24500540]

12. Richman EL, Kenfield SA, Stampfer MJ, Paciorek A, Carroll PR, Chan JM. Physical activity after diagnosis and risk of prostate cancer progression: data from the cancer of the prostate strategic urologic research endeavor. Cancer Res 2011 Jun 1;71(11):3889-3895 [FREE Full text] [doi: 10.1158/0008-5472.CAN-10-3932] [Medline: 21610110]

13. Kenfield SA, Stampfer MJ, Giovannucci E, Chan JM. Physical activity and survival after prostate cancer diagnosis in the health professionals follow-up study. J Clin Oncol 2011 Feb 20;29(6):726-732 [FREE Full text] [doi: 10.1200/JCO.2010.31.5226] [Medline: 21205749]

14. Friedenreich CM, Wang Q, Neilson HK, Kopciuk KA, McGregor SE, Courneya KS. Physical activity and survival after prostate cancer. Eur Urol 2016 Oct;70(4):576-585 [FREE Full text] [doi: 10.1016/j.eururo.2015.12.032] [Medline: 26774959]

15. Bonn SE, Sjölander A, Lagerros YT, Wiklund F, Stattin P, Holmberg E, et al. Physical activity and survival among men diagnosed with prostate cancer. Cancer Epidemiol Biomarkers Prev 2015 Jan;24(1):57-64 [FREE Full text] [doi: 10.1158/1055-9965.EPI-14-0707] [Medline: 25527697]

16. Wang Y, Jacobs EJ, Gapstur SM, Maliniak ML, Gansler T, McCullough ML, et al. Recreational physical activity in relation to prostate cancer-specific mortality among men with nonmetastatic prostate cancer. Eur Urol 2017 Dec;72(6):931-939. [doi: 10.1016/j.eururo.2017.06.037] [Medline: 28711382]

17. Yang M, Kenfield SA, van Blarigan EL, Batista JL, Sesso HD, Ma J, et al. Dietary patterns after prostate cancer diagnosis in relation to disease-specific and total mortality. Cancer Prev Res (Phila) 2015 Jun;8(6):545-551 [FREE Full text] [doi: 10.1158/1940-6207.CAPR-14-0442] [Medline: 26031631] 
18. van Blarigan EL, Kenfield SA, Yang M, Sesso HD, Ma J, Stampfer MJ, et al. Fat intake after prostate cancer diagnosis and mortality in the Physicians' Health Study. Cancer Causes Control 2015 Aug;26(8):1117-1126 [FREE Full text] [doi: 10.1007/s10552-015-0606-4] [Medline: 26047644]

19. Richman EL, Stampfer MJ, Paciorek A, Broering JM, Carroll PR, Chan JM. Intakes of meat, fish, poultry, and eggs and risk of prostate cancer progression. Am J Clin Nutr 2010 Mar;91(3):712-721 [FREE Full text] [doi: 10.3945/ajen.2009.28474] [Medline: 20042525]

20. Richman EL, Carroll PR, Chan JM. Vegetable and fruit intake after diagnosis and risk of prostate cancer progression. Int J Cancer 2012 Jul 1;131(1):201-210 [FREE Full text] [doi: 10.1002/ijc.26348] [Medline: 21823116]

21. Richman EL, Kenfield SA, Stampfer MJ, Giovannucci EL, Chan JM. Egg, red meat, and poultry intake and risk of lethal prostate cancer in the prostate-specific antigen-era: incidence and survival. Cancer Prev Res (Phila) 2011 Dec;4(12):2110-2121 [FREE Full text] [doi: 10.1158/1940-6207.CAPR-11-0354] [Medline: 21930800]

22. Peisch SF, van Blarigan EL, Chan JM, Stampfer MJ, Kenfield SA. Prostate cancer progression and mortality: a review of diet and lifestyle factors. World J Urol 2017 Jun;35(6):867-874 [FREE Full text] [doi: 10.1007/s00345-016-1914-3] [Medline: 27518576]

23. Pettersson A, Kasperzyk JL, Kenfield SA, Richman EL, Chan JM, Willett WC, et al. Milk and dairy consumption among men with prostate cancer and risk of metastases and prostate cancer death. Cancer Epidemiol Biomarkers Prev 2012 Mar;21(3):428-436 [FREE Full text] [doi: 10.1158/1055-9965.EPI-11-1004] [Medline: 22315365]

24. Chavarro JE, Stampfer MJ, Hall MN, Sesso HD, Ma J. A 22-y prospective study of fish intake in relation to prostate cancer incidence and mortality. Am J Clin Nutr 2008 Nov;88(5):1297-1303 [FREE Full text] [doi: 10.3945/ajcn.2008.26419] [Medline: 18996866$]$

25. Chan JM, Holick CN, Leitzmann MF, Rimm EB, Willett WC, Stampfer MJ, et al. Diet after diagnosis and the risk of prostate cancer progression, recurrence, and death (United States). Cancer Causes Control 2006 Mar;17(2):199-208. [doi: 10.1007/s10552-005-0413-4] [Medline: 16425098]

26. Dickerman BA, Giovannucci E, Pernar CH, Mucci LA, Hernán MA. Guideline-based physical activity and survival among US men with nonmetastatic prostate cancer. Am J Epidemiol 2019 Mar 1;188(3):579-586 [FREE Full text] [doi: 10.1093/aje/kwy261] [Medline: $\underline{30496346]}$

27. Rock CL, Doyle C, Demark-Wahnefried W, Meyerhardt J, Courneya KS, Schwartz AL, et al. Nutrition and physical activity guidelines for cancer survivors. CA Cancer J Clin 2012;62(4):243-274 [FREE Full text] [doi: 10.3322/caac.21142] [Medline: 22539238]

28. van der Bij AK, Laurant MG, Wensing M. Effectiveness of physical activity interventions for older adults: a review. Am J Prev Med 2002 Feb;22(2):120-133. [doi: 10.1016/s0749-3797(01)00413-5] [Medline: 11818183]

29. Demark-Wahnefried W, Morey MC, Sloane R, Snyder DC, Miller PE, Hartman TJ, et al. Reach out to enhance wellness home-based diet-exercise intervention promotes reproducible and sustainable long-term improvements in health behaviors, body weight, and physical functioning in older, overweight/obese cancer survivors. J Clin Oncol 2012 Jul 1;30(19):2354-2361 [FREE Full text] [doi: 10.1200/JCO.2011.40.0895] [Medline: 22614994]

30. Keogh JWL, Patel A, MacLeod RD, Masters J. Perceived barriers and facilitators to physical activity in men with prostate cancer: possible influence of androgen deprivation therapy. Eur J Cancer Care (Engl) 2014 Mar;23(2):263-273. [doi: 10.1111/ecc.12141] [Medline: 24134506]

31. Kuijpers W, Groen WG, Aaronson NK, van Harten WI. A systematic review of web-based interventions for patient empowerment and physical activity in chronic diseases: relevance for cancer survivors. J Med Internet Res 2013 Feb 20;15(2):e37 [FREE Full text] [doi: 10.2196/jmir.2281] [Medline: 23425685]

32. Golsteijn RH, Bolman C, Volders E, Peels DA, de Vries H, Lechner L. Development of a computer-tailored physical activity intervention for prostate and colorectal cancer patients and survivors: OncoActive. BMC Cancer 2017 Jun 26;17(1):446 [FREE Full text] [doi: 10.1186/s12885-017-3397-z] [Medline: 28651586]

33. Golsteijn RH, Bolman C, Volders E, Peels DA, de Vries H, Lechner L. Short-term efficacy of a computer-tailored physical activity intervention for prostate and colorectal cancer patients and survivors: a randomized controlled trial. Int J Behav Nutr Phys Act 2018 Oct 30;15(1):106 [FREE Full text] [doi: 10.1186/s12966-018-0734-9] [Medline: $\underline{30376857]}$

34. Mohamad H, Ntessalen M, Craig LC, Clark J, Fielding S, N'Dow J, et al. A self-help diet and physical activity intervention with dietetic support for weight management in men treated for prostate cancer: pilot study of the Prostate Cancer Weight Management (PRO-MAN) randomised controlled trial. Br J Nutr 2019 Sep 14;122(5):592-600. [doi:

10.1017/S0007114519001090] [Medline: 31177994]

35. Trinh L, Arbour-Nicitopoulos KP, Sabiston CM, Berry SR, Loblaw A, Alibhai SM, et al. RiseTx: testing the feasibility of a web application for reducing sedentary behavior among prostate cancer survivors receiving androgen deprivation therapy. Int J Behav Nutr Phys Act 2018 Jun 7;15(1):49 [FREE Full text] [doi: 10.1186/s12966-018-0686-0] [Medline: 29880049]

36. van de Wiel HJ, Stuiver MM, May AM, van Grinsven S, Aaronson NK, Retèl VP, et al. (Cost-)effectiveness of an internet-based physical activity support program (with and without physiotherapy counselling) on physical activity levels of breast and prostate cancer survivors: design of the PABLO trial. BMC Cancer 2018 Nov 6;18(1):1073 [FREE Full text] [doi: 10.1186/s12885-018-4927-z] [Medline: 30400784] 
37. Mehra S, Visser B, Dadema T, van den Helder J, Engelbert RH, Weijs PJ, et al. Translating behavior change principles into a blended exercise intervention for older adults: design study. JMIR Res Protoc 2018 May 2;7(5):e117 [FREE Full text] [doi: 10.2196/resprot.9244] [Medline: 29720358]

38. Kloek CJ, van Dongen JM, de Bakker DH, Bossen D, Dekker J, Veenhof C. Cost-effectiveness of a blended physiotherapy intervention compared to usual physiotherapy in patients with hip and/or knee osteoarthritis: a cluster randomized controlled trial. BMC Public Health 2018 Aug 31;18(1):1082 [FREE Full text] [doi: 10.1186/s12889-018-5975-7] [Medline: 30170586]

39. Groen WG, van Harten WH, Vallance JK. Systematic review and meta-analysis of distance-based physical activity interventions for cancer survivors (2013-2018): We still haven't found what we're looking for. Cancer Treat Rev 2018 Sep;69:188-203. [doi: 10.1016/j.ctrv.2018.07.012] [Medline: 30077954]

40. Winters-Stone KM, Kenfield SA, Van Blarigan EL, Moe EL, Ramsdill JW, Daniel K, et al. Effect of increasing levels of web-based behavioral support on changes in physical activity, diet, and symptoms in men with prostate cancer: protocol for a randomized controlled trial. JMIR Res Protoc 2018 Nov 15;7(11):e11257 [FREE Full text] [doi: 10.2196/11257] [Medline: 30442638 ]

41. Harris PA, Taylor R, Thielke R, Payne J, Gonzalez N, Conde JG. Research electronic data capture (REDCap)--a metadata-driven methodology and workflow process for providing translational research informatics support. J Biomed Inform 2009 Apr;42(2):377-381 [FREE Full text] [doi: 10.1016/j.jbi.2008.08.010] [Medline: 18929686]

42. Stewart AL, Mills KM, King AC, Haskell WL, Gillis D, Ritter PL. CHAMPS physical activity questionnaire for older adults: outcomes for interventions. Med Sci Sports Exerc 2001 Jul;33(7):1126-1141. [doi: 10.1097/00005768-200107000-00010] [Medline: 11445760]

43. Rimm EB, Giovannucci EL, Stampfer MJ, Colditz GA, Litin LB, Willett WC. Reproducibility and validity of an expanded self-administered semiquantitative food frequency questionnaire among male health professionals. Am J Epidemiol 1992 May 15;135(10):1114-26; discussion 1127. [doi: 10.1093/oxfordjournals.aje.a116211] [Medline: 1632423]

44. Eldridge SM, Chan CL, Campbell MJ, Bond CM, Hopewell S, Thabane L, PAFS consensus group. CONSORT 2010 statement: extension to randomised pilot and feasibility trials. Pilot Feasibility Stud 2016;2:64 [FREE Full text] [doi: 10.1186/s40814-016-0105-8] [Medline: 27965879]

45. Santarossa S, Kane D, Senn CY, Woodruff SJ. Exploring the role of in-person components for online health behavior change interventions: can a digital person-to-person component suffice? J Med Internet Res 2018 Apr 11;20(4):e144 [FREE Full text] [doi: 10.2196/jmir.8480] [Medline: 29643048]

46. McTigue KM, Conroy MB, Hess R, Bryce CL, Fiorillo AB, Fischer GS, et al. Using the internet to translate an evidence-based lifestyle intervention into practice. Telemed J E Health 2009 Nov;15(9):851-858. [doi: 10.1089/tmj.2009.0036] [Medline: 19919191]

47. Mohr DC, Cuijpers P, Lehman K. Supportive accountability: a model for providing human support to enhance adherence to eHealth interventions. J Med Internet Res 2011 Mar 10;13(1):e30 [FRE Full text] [doi: 10.2196/jmir.1602] [Medline: 21393123]

48. Bibault J, Chaix B, Guillemassé A, Cousin S, Escande A, Perrin M, et al. A chatbot versus physicians to provide information for patients with breast cancer: blind, randomized controlled noninferiority trial. J Med Internet Res 2019 Nov 27;21(11):e15787 [FREE Full text] [doi: 10.2196/15787] [Medline: 31774408]

49. Greer S, Ramo D, Chang Y, Fu M, Moskowitz J, Haritatos J. Use of the chatbot 'Vivibot' to deliver positive psychology skills and promote well-being among young people after cancer treatment: randomized controlled feasibility trial. JMIR Mhealth Uhealth 2019 Oct 31;7(10):e15018 [FREE Full text] [doi: 10.2196/15018] [Medline: 31674920]

50. Piau A, Crissey R, Brechemier D, Balardy L, Nourhashemi F. A smartphone Chatbot application to optimize monitoring of older patients with cancer. Int J Med Inform 2019 Aug;128:18-23. [doi: 10.1016/j.ijmedinf.2019.05.013] [Medline: 31160007]

51. Kelleher SA, Dorfman CS, Plumb Vilardaga JC, Majestic C, Winger J, Gandhi V, et al. Optimizing delivery of a behavioral pain intervention in cancer patients using a sequential multiple assignment randomized trial SMART. Contemp Clin Trials 2017 Jun;57:51-57 [FREE Full text] [doi: 10.1016/j.cct.2017.04.001] [Medline: 28408335]

52. Phillips SM, Collins LM, Penedo FJ, Courneya KS, Welch W, Cottrell A, et al. Optimization of a technology-supported physical activity intervention for breast cancer survivors: Fit2Thrive study protocol. Contemp Clin Trials 2018 Mar;66:9-19 [FREE Full text] [doi: 10.1016/j.cct.2018.01.001] [Medline: 29330081]

53. Morey MC, Snyder DC, Sloane R, Cohen HJ, Peterson B, Hartman TJ, et al. Effects of home-based diet and exercise on functional outcomes among older, overweight long-term cancer survivors: RENEW: a randomized controlled trial. J Am Med Assoc 2009 May 13;301(18):1883-1891 [FREE Full text] [doi: 10.1001/jama.2009.643] [Medline: 19436015]

\section{Abbreviations}

AE: adverse event

CHAMPS: Community Health Activities Model Program for Seniors

FFQ: food frequency questionnaire

OHSU: Oregon Health and Sciences University 
NIH: National Institutes of Health

P8-I: Prostate 8-I

UCD: University of Colorado Denver

UCSF: University of California San Francisco

Edited by $G$ Eysenbach; submitted 14.04.20; peer-reviewed by $W$ van Harten, $C$ Short; comments to author 13.06.20; revised version received 07.08.20; accepted 11.11.20; published 31.12.20

Please cite as:

Chan JM, Van Blarigan EL, Langlais CS, Zhao S, Ramsdill JW, Daniel K, Macaire G, Wang E, Paich K, Kessler ER, Beer TM, Lyons $K S$, Broering JM, Carroll PR, Kenfield SA, Winters-Stone KM

Feasibility and Acceptability of a Remotely Delivered, Web-Based Behavioral Intervention for Men With Prostate Cancer: Four-Arm Randomized Controlled Pilot Trial

J Med Internet Res 2020;22(12):e19238

URL: http://www.jmir.org/2020/12/e19238/

doi: $\underline{10.2196 / 19238}$

PMID: 33382378

(CJune M Chan, Erin L Van Blarigan, Crystal S Langlais, Shoujun Zhao, Justin W Ramsdill, Kimi Daniel, Greta Macaire, Elizabeth Wang, Kellie Paich, Elizabeth R Kessler, Tomasz M Beer, Karen S Lyons, Jeanette M Broering, Peter R Carroll, Stacey A Kenfield, Kerri M Winters-Stone. Originally published in the Journal of Medical Internet Research (http://www.jmir.org), 31.12.2020. This is an open-access article distributed under the terms of the Creative Commons Attribution License (https://creativecommons.org/licenses/by/4.0/), which permits unrestricted use, distribution, and reproduction in any medium, provided the original work, first published in the Journal of Medical Internet Research, is properly cited. The complete bibliographic information, a link to the original publication on http://www.jmir.org/, as well as this copyright and license information must be included. 